\section{A method for identifying eggs laid by individual birds}

\author{
MICHAEL C. APPLEBY and HELEN E. McRAE \\ Agricultural Research Council's Poultry Research Centre, \\ Roslin, Midlothian, Scotland
}

A method for identifying eggs laid by different subsections or individual members of groups of domestic hens is described. Fat-soluble dyes are placed in gelatin capsules and fed to selected birds. These dyes produce discrete colored bands in the yolks of eggs laid by those birds. The presence of dye in eggs can be detected through the shell, and different patterns of rings can be distinguished by boiling and sectioning eggs. Application of the method to other species and other circumstances is considered.

If fat-soluble dye is given orally or intravenously to female birds whose ovaries contain developing eggs, it is laid down in discrete layers of color in the yolks of those eggs (first described by Riddle, 1908; used recently by, e.g., Gilbert, 1970). This phenomenon has been used to distinguish the eggs of individual birds in groups of up to three (Harris \& Muir, 1973; Hughes, 1977). We have developed a technique for identifying eggs from larger numbers of individuals or from birds forming subsections of groups. The technique is described here as it was developed for domestic hens.

\section{MATERIALS AND METHODS}

Two commonly available dyes are used in the technique: Scarlet R. Michaelis and Sudan Black B. These can be used separately to give distinct red and green colors, respectively, in the yolk. In addition, the two dyes can be combined in equal weights to produce a purple color.

Dye is mixed with an equal weight of glucose, to facilitate handling, and is placed in a size 4 gelatin capsule (Bacon \& Skala, 1968) to give a dose of between 50 and $100 \mathrm{mg}$ of one of the three colors. Individual capsules are then given orally to selected hens. These produce clearly identified colored rings in the yolks of eggs laid from the 2 nd to about the 9 th day after administration. As a result, weekly dosing is sufficient to distinguish among the eggs of four different individuals or of four sections of a group (for example, in the first, second, third, and fourth quarters of a hierarchy) (Table 1), if care is taken with the identification

We are grateful for the assistance of Alan Gilbert, Barry Hughes, Jim Peddie, and Karen Beattie with methods of dye administration, and of Ian Duncan in discussion. Funding is provided by a grant from the Commission of the European Communities to the Agricultural Research Council.
Table 1

Examples of Schedules for Identifying Eggs From 4, 21, and 42 Hens or Groups of Hens. Capsules of Red (R), Black (B), or Purple (P) Dye are Given on the Indicated Days of 7-Day Schedules

\begin{tabular}{|c|c|c|c|c|c|c|}
\hline \multirow[b]{2}{*}{ Hen } & \multicolumn{6}{|c|}{ Day } \\
\hline & 1 & 2 & 3 & 4 & 5 & 6 \\
\hline \multicolumn{7}{|c|}{ 4-Hen Condition } \\
\hline 1 & $\mathbf{R}$ & & & & & \\
\hline 2 & B & & & & & \\
\hline 3 & $\mathrm{P}$ & & & & & \\
\hline 4 & & & & & & \\
\hline \multicolumn{7}{|c|}{ 21-Hen Condition } \\
\hline 1 & $\mathbf{R}$ & & & & & \\
\hline 2 & $\mathbf{R}$ & $\mathbf{R}$ & \\
\hline 3 & $\mathbf{R}$ & & \multicolumn{4}{|c|}{$\mathbf{R}$} \\
\hline 4 & $\mathrm{R}$ & B & \\
\hline 5 & $\mathrm{R}$ & & \multicolumn{4}{|c|}{ B } \\
\hline 6 & $\mathbf{R}$ & $\mathrm{P}$ & \multirow{2}{*}{\multicolumn{4}{|c|}{$\mathbf{P}$}} \\
\hline $7^{*}$ & $\mathrm{R}$ & & & & & \\
\hline \multicolumn{7}{|c|}{ 42-Hen Condition } \\
\hline 1 & $\mathrm{R}$ & & & & & \\
\hline 2 & & & & $\mathrm{R}$ & & \\
\hline 3 & $\mathbf{R}$ & $\mathrm{R}$ & & & & \\
\hline 4 & & & & $\mathbf{R}$ & $\mathbf{R}$ & \\
\hline 5 & $\mathbf{R}$ & & $\mathbf{R}$ & & & \\
\hline $6^{*}$ & & & & $\mathbf{R}$ & & $\mathbf{R}$ \\
\hline
\end{tabular}

*Etc., exchanging colors.

(Hughes, 1977). Individual hens vary in the rate at which they lay down yolk, but the eggs of hens that have been given dye capsules 2 or 3 days apart can be distinguished reliably. The labeling of larger numbers of hens than before is therefore possible (Table 1).

It may be possible to detect the presence of dye in eggs, and to distinguish at least black and red dyes, simply by candling the eggs (placing them over a bright light). Black dye can be seen in brown-shelled eggs for about 2 days, and either dye can be seen in whiteshelled eggs for about 3 days after its first appearance. A method that is more reliable and that is applicable for a longer period is to break the eggs and stir the yolks. However, to detect dye throughout the duration of its effect, and to distinguish different rings, eggs are hardboiled and the yolks are cut across the center with a wire or sharp knife.

Alternative dyes used successfully in studies of ovum growth have included Sudan III and Sudan IV, both red, (e.g., Bacon \& Skala, 1968; Warren \& Conrad, 1939), and Evans blue, which gives a color similar to that which the black dye gives, but has to be injected (Gilbert, 1970). Different doses of dye may give colored layers of different thicknesses (Warren \& Conrad, 1939) or intensities in the yolk (Oribe, Kameyama, \& Kayano, 1975). The number of days over which dye is effective may 
vary among species (turkeys-Bacon \& Cherms, 1968; quail-Bacon \& Koontz, 1971; emus-Hirsch \& Grau, 1981).

The method is particularly applicable to hens and other domestic poultry, which can be handled easily and from which eggs can be removed. However, it may also be used in other species and in other circumstances, since dyes apparently have no ill effects on egg production (Bacon \& Skala, 1968). If dye cannot be given orally or by injection (for methods, see Warren \& Conrad, 1939), it may be mixed with food, in a loose form (Gage \& Gage, 1908), or given in capsules. In cases in which it can be detected without breaking the eggs, as described above, the eggs can then be allowed to develop until hatching occurs. Furthermore, coloration from the dye occurs in the fat deposits of chicks after hatching, and the offspring of different mothers can therefore be distinguished (Gage \& Gage, 1908; Rogers, 1910). The technique described might be particularly valuable in studies of species in which several individuals lay in the same nest.

\section{REFERENCES}

Bacon, W. L., \& Cherms, F. L. Ovarian follicular growth and maturation in the domestic turkey. Poultry Science, 1968, 47, 1303-1314.
Bacon, W. L., \& Koontz, M. Ovarian follicular growth and maturation in Coturnix quail. Poultry Science, 1971, 50, 233-236.

Bacon, W. L., \& Skala, J. H. Ovarian follicular growth and maturation in laying hens and the relation to egg quality. Poultry Science, 1968, 47, 1437-1442.

Gage, S. H., \& Gage, S. P. Sudan III deposited in the egg and transmitted to the chick. Science, 1908, 28, 494-495.

Gilbert, A. B. Yolk deposition in the chicken oocyte and its relationship with ovulation. Journal of Reproduction and Fertility, $1970,23,539-540$.

Harris, P. C., \& Muir, F. V. Egg production of individual birds in multiple density cages. Poultry Science, 1973, 52, 2035.

HrRsch, K. V., \& GraU, C. R. Yolk formation and oviposition in captive emus. Condor, 1981, 83, 381-382.

Hughes, B. O. The absence of a relationship between egg production and dominance in caged laying hens. British Poultry Science, 1977, 18, 611-616.

Oribe, T., Kameyama, K., \& Kayano, K. Studies on yolk formation of the domestic hen. I. On the morphology of Sudan layer formed in the egg yolk after feeding Sudan III. Bulletin of the Hiroshima Agricultural College, 1975, 5, 189-199.

RidDLe, 0 . The rate of growth of the egg-yolk in the chick, and the significance of white and yellow yolk in the ova of vertebrates. Science, 1908, 27, 945.

Rogers, C. A. Feeding color-An aid in studying physiological development. International Association of Instructors and In. vestigators Poultry Husbandry Proceedings, 1910, 77-81.

Warren, D. C., \& Conrad, R. M. Growth of the hen's ovum. Journal of Agricultural Research, 1939, 58, 875-893.

(Manuscript accepted for publication December 21, 1982.) 